\title{
Flower and Chicken Painting from the Symbol's and Myth's Perspective
}

\section{Fatemeh Shirsepehr ${ }^{1}$}

\author{
Ali Asqar Shirsepehr2 \\ ${ }^{1}$ Department of Painting, Faculty of Art and Architecture, Tarbiat Modares University, Tehran, Iran \\ 2Department of Painting, Faculty of Handicrafs, Isfahan University Of Art, Isfahan, Iran \\ "Corresponding: Fatemeh Shirsepehr, e-mail: shirsepehr.tmu@hotmail.com
}

\section{Doi:10.5901/mjss.2016.v7n2s1p409}

\section{Abstract}

Chicken and flower painting could be accounted as s school in Iranian typography, however determining its place and its analogy with the European paintings for the people acquainted to the Iranian culture would be under question. Especially finding the 4 thousand years old painting of Simorgh and Vispuish tree makes us think that main symbols of flower and chicken which is plant and bird, is taken from the Simorgh and Vispuish flower. For this purpose investigating bird's (Simorgh's) and plant (tree) myths was taken place. Interestingly Simorgh which in Avesta is called "Saen" has been compared with other mythical birds like Phoenix and eagle and its magical features and its irrefrangible relation with Vispubish tree which contains the seeds of all plants and its healing feature was investigated. From one side, Sohrevardi words which carries Iranian thoughts prove the relation between Iranian perfectionism and these two myths. There were major changes after the entrance of Islam in Iran, however these two myths survived, tree in the shape of plant and Phoenix in the shape of a small bird was painted beside it. If this design was European, it would not be so acceptable for the society and under the effect of fashion, it would disappear very soon. Social mindset of the past has effected its formation and survival.

Keywords: Myth, Flower and Chicken, Tree.

\section{Introduction}

Investigating and examining the ancient literature and artistic works from the past and their analogy are the instruments for the study of myths and symbols, so that the true existence of myths could be understood and higher than semisanctity, their hidden values which have been transferred through centuries and millenniums could be understood and to see why in this modern society they are emerged and what has been their producing social mindset. Flower and chicken painting are two deep and symbolic concepts of plant and bird which are presented in religious ancient texts, seals, pottery, Reliefs. Flower and chicken related paintings are reflected in magazines and generally in artistic works before and after Islam in Iran. Plant participate in judgment day, in literary, mythical and religious texts plant is referred and in old past rituals it had been used significantly and it has hold its ancient function up to now and in different material and spiritual aspect it is reflected in human life. From the other hand, chicken has the same position. Either mythical birds, like Phoenix, Epoush, Komak and Engha, or small birds like Nightingale, Canary and Pigeon also are reflected both in literature and paintings.

Flying feature and their mysterious existence sometimes grant mysticism aspect to them. Even though there were a banning of animal painting in the first century of Islam, the picture of Phoenix over the portico of mosques, the picture of flower and chicken in single paintings are seen and so the combination of two picture of plant and bird beside each other could not be an imported role and it is absolutely rooted in Iraninan thought.

\section{Explanation of Problem}

The painting art of chicken and flower in recent centuries has been increasingly suggested and has taken the brand name of "flower and chicken" and there are a lot of ideas expressed about it. Some emphasis over its apparent shape and they believe it is inspired by European paintings. But the existence of 4 thousand year old flower and chicken makes us to think more about this matter and philosophy of this type of painting to be discussed and consequently its internal mythical and philosophical approach would be examined. 


\section{Literature Review}

\subsection{Definition of myth}

In the encyclopedia of descriptive critic and literary views (Fatemeh Modarsei) myth has been defined as: "myth is an Arabic word originated from Historia of Greece which means story, search and insight. The word of Myth which is originated from Greece's word of Mitus interpreted as myth." Oxofrd English dictionary says: "myth is a narration with an absolute legendry aspect..." however this definition is not true, because it is possible that myths and mythical stories have no historical documentary. Although they carry a concept or some concepts and play an important role in national and religious beliefs of people and territories. Myths are mirrors which reflect images from millenniums and where the history and archeology are silent, myths speack and human culture is taken to our time from long distances and high thouts and developed logic of unknown but insightful people are accessible for us (Amuzegar, 2002). The most significant function of myths are the explanation and justification of natural and cultural truths (Esmail, 1998).

The function of myth may be the dramatized explanation of votes and views of a society, not only for integrating it to the social conscience and its values and the ideals which have been followed from one generation to the other, but more over for the explanation of its very own existence, elements, relatons, harmonies and tensions which form it, and also for the establishment of rules and and performance it is a costume which without it everything in the society would collapse (ibid, p 49).

\subsection{Symbol of tree}

\subsubsection{The symbolic concept of tree (plant) in ancient Iran}

Many researchers have studied on the symbols, especially symbol of tree and plant. Here the variety of views are presented and then with investigation and contrastive analysis of western and eastern ideas over the symbol of tree, it would be compared to the Iranian concepts. The first samples of plants are found on pottery, seals and stones in Iran. The Elamite world is full of images of plants and trees; such as Bronzes in Lorestan, Marlik, Amlash and Ziviey. In the period of Arian Iranians, in the age of Medians, Achaemenian and Parians the mythical image of tree is are seen, (G. Watty, 2000, p46). The mythical importance of tree among Iranians could be understood from the story of creation of first human parents that is Mashi and Mashianeh. "The first human couple grew from the earth in the shape of integrated plant by the casted semen of Kiomars..." (Hinlez, 1989, p 93). The sanctity of the plant is rooted in its life-giving and fertility aspect. For the same reason in the thoughts of first men, the picture of "life's tree" is a tree with the shape of a plant with a variety of holy branches; and in ancient civilizations through the world it was considered the symbol of fertility and growing and the monitor of good and blessing. Its leaves had the healing effect for human pains and this is a role which was used especially in the decorative and coding arts of Mesopotamia from 3500 BC and in Iranian Sassanid's era. In ancient myths, Holy tree with the same concept and meaning is an equvelent for the "Life's tree" (Marzban, 1998, p.352).

Monik Devi Kour quotes Gouble Aloublayi in the book of (moving symbols) suggests that the tree of life between the twin Rivers in Mesopotamia in Iran has been developed to the Holy plant (Douvio Kour, 1994, p14). Mircha lliadeh also believes that " the tree of life and renew of life in Iranian traditions is Houm which grows on Iranian mountations" (Aliadeh; 1997, 278).

\subsubsection{The position of tree in Zoroastrian and Islamic religions}

According to the Avesta and Bandehesh texts, the creation has occurred in two forms of material and Enamel: "Ahouramazda, first created the world as an example and before creating the material world, the Enamel world was created and gave its Enamel Gem for his Gem (Shams, 206(. He created 6 Amshspand who were the guards of Enemal world and the earth's Enemal is Sepandarmaz. Emshspendan have some duties which one of them is guarding the plants. Bandehesh says: "fourthly, plant was created, first it was grown on the earth with some legs up, without any branches, skin and thorn, it was fresh and sweet, it contained all strengths of all plants. He created water and fire to help the plant, since body of each plant has a watery nature and the fire of four fingers is beside them to grant force of growing" (Bahar, 2001, p. 40). Chapter 8 of Bandhesh reads as: "fourth campaign was from the plant, when it was dried, Amordad Amshaspand which owns the plant, grinded and softened it and mixed it with the water gained from the knife. Knife rained that water over all the earth. Plant was grown on all earth likewise hair over the head of people. Form that original type, tens of thousands originated to heal the tens of thousands of diseases that evil had created against the 
creatures. From that tens of thousands, hundred thousand types of plant originated. From all of them the seed of "Vastokhmeh" (container of a vast number of seeds" was created. In the sea of Frakhkert all type of plants are originated from that tree and grew from that on. Near that tree the tree of "Goukaran" was created to prevent aging of people (Bahar, 1997, p45). Avesta says: "the tree that has grown in the middle of the Farkh;art sea, the tree which contains good and effective drugs which is called "Vispouyesh" (healer of all types of pains" and it contains the seeds of all plants." (Soltani, 1993, p 29). In the majority of religious literature the tree of "Houm, Geokren or Houm Sepid" is also referred as a life-giving tree and anti- pain and anti-disease which is grown in Faradhdert Sea beside Vispouyesh tree: Houm is one the Irian ancient God. This plant grows on mountains and featured with gold or soft gold branch. Its essence brings drunkenness and it is healing." (Mir Shokrayi, 2000, p 53). On one the features of Houm is drunkenness and it is interesting that a mixture of it has been prescribed to some people to see the other world. King Kavous and Ardaviraf are the most prominent among them.

In addition to the recalled trees (Vispouyesh and Houm) in ancient Iran there were other trees like plane, cedar, Sycamore, vine and pomegranate that they were symbolic trees and some of them were life-giving and had sanctity. Samuel K. Adie notes: "Persian kings always respected plane trees and there a gold plane tree and a gold vine tree in their courts which were placed in their bedrooms and plane was decorated with lots of Gems" (Bahar, 2000, p 6). Herodotus says that the last Median king, dreamed her daughter who became the mother of Cyrus grew from the belly of a vine and covered throughout the Asia. if we notice that the vine in Iranian myths is the symbol of blood and blood is the main power of life and also in the Achaemenian state remaining of some ancient local rituals of matriarchal which according to them kingdom is extended from women. A vine which wraps a plane tree could be considered as the symbol of blood and endurance of Achaemenian kingdom" (Bahar, 2000, p. 6).

In Iranian era of Achaemenian and Sassanid, the tree of cedar was taken into account as the tree of the life and the role of this tree as the Relief in Persepolis is significantly seen. The paintings of the decorative plants in the architectural art works of the Sassanid's era has vastly used from the decorative painting of plants which some of tame are taken from the holly tree. "The general view of Manicheans about the universe is that they consider two roots or two tress as the main origin of the life: one is the light and th other is the darkness or tree of the life and death" (Samady, 1988, w 130). The other old tree which is called in ancient period and its painting could be observed on the oldest potteries to metal plates in the Sassanid's era, is the "Tree of Moon", analogy between Tree and Moon is from this point of view that both of them develop an pleasant shadow. Moon after hot radiances of the sun, and tree with making shadow. Moon's admiring in Yasna comes along with praying and Brasm and Houm and firewood and likewise which Bram is the new narrow branches which are cut from the Houm tress, which is a tree like Tamarisk tree and if there is no Tamarisk, the pomegranate tree is used (Salehi, 1993, p 20). As the final word about the case of tree in the Iranian culture before Islam the tree of Asourik tree should not be neglected. Asourik is the title of a literary book and it is one of very rare literary texts which has remained from the era of before Islam in Iran. The subject of it is a debate between the Palm tree and the goat in the Parthian Pahlavi language.

Appearance of Islam was taken to the world of symbols, as well and with its ideology and Philosophy brought change and development in them. In Iran before Islam ancient believes were dominant and the symbols also had the very special concepts of that ideology, however, Islam appearance in Iran and Iranians' converting to Islam caused the Iranian late Ideology to be mixed with Islam's Ideology and as a result we are witnesses of changes in some cultural and Art's arena today. So not only we are witnessing any contextual withdrawal, but we are also witnessing a kind of contextual and conceptual evolution, produced from compounding with Islamic mysticism. As an instance, in ancient Iran, for the funeral ceremony of kings, like Cyrus, participants in the ceremony brought a cedar tree from its roots and carried it behind the body. Cedar tree has been the symbol of male gender and Palm and vine tree has been the symbol of female gender in ancient Iran. This custom which takes the tree as the symbol of life in the funeral ceremonies was renewed in Tasua and Ashura ceremonies in the Safavi era, and it was changed to Alam (flag) and Kotal (banner) which one of them was like a palm tree and another was like a cadre tree. And today this is a main form of symbolic costume in Islam. And the Achaemenian tree of life as a Relief and in the plaster Relief of Sassanids as the Acanthus's bushes and after Islam as the picture of vases in the inscriptions and carpet's designs have been presented and an abstract form of it is the same Arabesque drawings which starts from a point in a design and covers throughout the cadre. This is the figurative abstract pattern of Touba, the tree from paradise referred in holy Quran and its interpretations have been taken from Quran and other religious advices and sayings ( Ansari, 1999, p 119).

The name of different trees like Touba, Palm, Olive, Figs, Pomegranate and others have been appeared in holy Quran so many times and their symbolic meanings are so profound and valuable. It would possibly be explained in this way that "nature" for human is the first material expression of god the great.There may not be anything like the tree that could remind the thought of perfection, since the tree has had the time's and place's potential for growing and perfecting, 
since its branches are directed out and up and its perfection is not closed, it is, however, open up. Holy Quran uses the same example for its own, it uses the word of "pure", since it is the best words: "didn't you see how the God gave example?" the pure word (Kalameh Tayebeh) is like a pure tree (Shajareh Tayebeh) that its roots are standing inside the earth and its branches are in the sky. So it should not be strange for us that one of the most important decorations of purification of Quran is a tree called "Shajireh" and there should not be any doubt about it that its purpose would be pointing to pure word. (Lingz, 1998, w 73).

In the Momenoon's (Believers) chapter of holy Quran, 20th verse reads: "from the Sinai Mountain grows a tree which produces the oil and bread for eaters" in chapter Safat, verses 144-146 read: "then as he was ill (Joseph majesty) we put him on a dry land and grew a tree over him from the type of Kadvin". In the Mary's chapter, verses 23-25 read: "until the pain of labor took him toward a palm tree .... Take the limber of the tree toward yourself and shake it till the fresh dates fall down". The God in Anam chapter, the $99^{\text {th }}$ verse points out the trees as a sign for the people: "he is who falls from sky the water, then grows different types of plants from it and brings out green shoots which produces dense granules and from the palm tree blossoms grow closed grapes and there are also gardens of grapes, olive and pomegranate which some are similar and some are not ... absolutely there are some signs in them for the people who are believers".

It could be said that the greatest tree in Quran is Touba (the eternal tree) which is grown in paradise. It branches are extended to the all paradise residents' houses and the second visit between the prophet and Gabriel took place under it. It is worthy to add that the symbol or concept of tree in God's word take the hell's figure which its place and sanctity is against Touba and it is called "Zaghoum tree" which grows in the hell. And in Quran (Safat chapter, verses 64-67) it is mentioned that the Zaghoum tree is for the punishment of the wicked and it is grown from the burning fire and its fruits are like the heads of devils.

"In all the preceding texts, this tree whatever we call it, like all symbols lives single and alone. As the Rose bush or SadBarg (Hundred Leaves) in the flower and chicken works is painted. And its loneliness recalls Phoenix, Phoenix, Homa, Sinmoro, chichen of ritusnous, Chicken of Amen and other legendary chickens which live alone like the chicken in flower and chicken paintings. The features of all these symbols are added by the beliefs of the same period of time. Although at the end these beliefs get the equivalent meanings and the very meaning sharing shows that the fundamental concept of these legendry symbols in the world of words and picture may never get changed" (Shahdady, 2012, p84).

\subsection{Symbol of Bird}

\subsubsection{Symbolic concept of bird (chicken) in ancient Iran}

Flower and chicken in artistic Iranian custom of painting is one of the branches of the art of typography. A collection of arts like Miniature, Illumination, Flower and Chicken, flower and bush and ... which are the ways of its rising and developing in a fundamental way are integrated with other arts like calligraphy and especially book illustration. As a matter of fact these arts have provided the grounds of effectiveness and dynamics of typography in all of its branches. Effectiveness of bird and flower in Iranian art has a long background which has fundamentally taken its roots from Iranian culture.

The background of birds' names and generally the word of chicken (Morgh) have a legendry and mythical load and take us to the world of myths. An era which the human mind was not able to discriminate complex concepts from natural aspects, the features like the Eagle's bulk, form, speed, high distance flying and turning in the sky had taken his attention. Its accommodation in the peaks of mountain and its victory over all other birds in hunting blazoned this living entity as an unearthly, supernatural and mysterious for human. And this is the same period that initial representations of life strengthens, like the sun, the moon, water, earth etc. were identified and named as different Gods. Similarity between the movement of sun (the most significant and important strength of nature) to the movement of eagle in the sky which were seen at the same level by the man of those days, in the temporal mythical travel in the believes of three civilizations of Egypt, Mesopotamia, and Khuzestan, and in Send valley have tied the fate of these two together. (Shahdady, 2013, p 95).

Logo of Phoenix had possibly been the formal sign of Sassanid's emperor. Outside wall of Tagh Bostan King Parviz's cloth is decorated with the sign of Phoenix. In Samarkand city in the western part of Afrasiab wall there is a relief of a kind or prince who is wearing a Phoenix sealed clothing. This typography belongs to Yazdgerd the $3^{\text {rd }}$, the last king of Sassanid's dynesty. Kingdom seal of Sassanid dynasty is a Phoenix which its tail is from peacock, its body is from Eagle and its head and paws are from lion. Beside the Temple of Bokhara there was a place for peacock accommodation. Since the spots on the tail of peacock is like eye it could be taken as the symbol of "Mehr Izad" (God's mercy) which has 
10 thousands eyes and guards all the pastures and living creatures. In addition he could be the guard of fire and holly tree (the tree of life or Keshmirian Cadre). For this purpose it has been designed in both sides of the tree. Meanwhile in Sanskrit language peacock is named "mayora" which semantically is close to the word of "Mehr" (mercy)

\subsubsection{Symbolic concept of bird (Morgh) in religious and literary texts.}

It may be told that phoenix (Simorgh) is one of the most important living creature in Persian literature. Many scholars from the late past has paid attention to this mythical Iranian bird and its similarities with other birds like Cyena, Indian Groudai, Varghan, Krishift, Amrou and Kamrouy in Avesta, Chamaroush and Kamak in Pahlavi literature, Arabic Angha, Homa and Ghoghnous in Persian literature, Greek Phoenix, Acadian Anzavi and Sirang in Folk literature. Later Phoenix (Simorgh) was taken from mythical field to other fields like Epic, mystic, art, typography, pug, metalworking etc. its etymology from Avesta is "Caene" which possesses magical features of feather, nurture, championship claim, relation with god, healing and life giving, relation with eternal plant and etc. In Avesta it is noted: "if you are up on a tree which accommodates nest of a Phoenix and it is grown in the middle of Farakhkart sea, it is a tree which has good drugs and it is called the doctor of all" (Doustkhah, 1982, p 400). Its nest heals and it is made of glass (Minooei) and it fulfills your needs and desires and cures your pains, it is somehow an answer to human needs, but its bulk is large and the origin of a sacred power. May victory of Bahram encompasses this house and herds of cows, as Simorgh and fertile clouds encompass the mountains" (ibid, p 439). This plant of "Vas Tokhmeh" (carrier of all types of seeds) is the place of "Simorgh", too. Simorgh in ancient Iran is the most important mythical living creature, it is a symbol of power and greatness which grants the victory of Kings (Fare Kiani) and herald of victory and healing, wizard and also thwarter of magic. Such a wonderful bird is nested over the Vispuyesh tree and interestingly some researchers suggest that Simorgh's healing feature is driven from the tree which it nests on (Soltani, 1993, p29). Simorgh is the most significant example of symbolic birds in Iranian culture and literature, integrated with the plant and with its growing and birth, this bird which is called "Angha" in Islamic tradition, is the same "Sin Moro" in Pahlavi. Divine nature of Simorgh among all Persian books about Iranian culture before Islam is presented in Shahname more than any other place. According to Shahname all life of Rostam's family is integrated with Simorgh and Simorgh amazingly gives relieves.

Metamorphosing of the symbolic concept of Simorgh into Islamic culture and the way of transferring from mythical motifs to the field of exemplified expressions in the Sohrevardi's thoughts (1170-1218) found the most clear, abstract and eloquent expression. Sohrevardi who was trying to renew pre Islam Iranian cultural ideas in the light of Islamic cultural concepts in such a systematic way and based on eastern ideas in re-interpreting the stories of Shahname which he believes they are full of the signs of ancient Iranian wisdom, raised Simorgh to a high position which portrays the god. The first portrays of bird and chicken in the books goes back to Islamic school of Baghdad. The symbolic position of birds does not exclusively belong to Simorgh, but in Attar's Mantegholeyr different dispositions and characteristics which each symbolic bird possesses is mentioned. Simorgh after Islam was known as the code of Gabriel. Large bulk, glory and beauty, feather and wing, nurturing (Simorgh nurtures Zal and Gabriel nurtures poor children of Israel), healing effect (Simorgh heals Rostam's and his horse's (Rakhsh) wounds and Gabrial heals Prophet's wound) and accommodation on the holy tree (Simorgh accommodates on the tree of Hroisp Tokhmak and Gabriel accommodates on the Sadrol Montaha (eternal tree)) are among the shared features which could be mentioned about these two and the last feature shows integration of Gabrial with plant (Pournamdarian, 1995, p 44).

"From the third and fourth century in solar system the picture of Simorgh on the potteries in Neishapur is seen. In the Patriarch and Teymoury era the picture of Simorgh for the decoration of structures in the form of tiling have been used" (Changiz and Rezalou, 2011). In the Safavi era the picture of Simorgh comparing to the past periods and also comparing to the picture of peacock was used lesser. And the picture of small birds like pigeon or Nightigle replaced the picture of Simorgh in Iranian typography.

In the 3 civilization (Iran, Egypt and Mesopotamia) initially, kings were the representative of god on the earth and they repeated his action and then found a shared character with Him and in the next phase they turned into his visualization. However in Iranian civilization, even though there are some legendry characters like KeyKhosro and Freidoun, they would get close to such a position, they would never take a divine position and they would never get an absolute power and this is related to Iranian faith. So that the bird as the symbol of divine power of king (eagle) transferred to the concept of flying, that is a collection of features like flying high and sun and light's radiation and infinite light and the mark of victory and glory and by the name of Varghan (winging) it entered Avesta. In Avesta it is noted: "in the period of Jamshid kingdom, there was neither coldness nor hotness, neither oldness, nor death, there were no devil jealousy. (It had been like this) before he lied and tried to not tell the truth. Starting lying, Farr (greatness) apparently ran away from him into the body of a bird. After breaking of Far from him, he was wandered and defeated against a rival 
enemy. When Farr broke from Jamshid the son of Viunghan and entered the body of Varghen the bird, Mehr took that Farr. For the second time Farr broke from Jamshid the son of Viunghan and entered the body of the bird. This time Freidoun the son of Abtin took the Farr and he became the most victorious among people except Zoroaster. He defeated the horned dragon and killed it" (Shahdadi, 2013).

\subsection{Investigating the relation between symbolic meaning of tree and Simorgh (Flower and Bird)}

Simorgh in ancient pictures has been painted on the tree or it feature, tail and tissues is integrated with plants. Because in the pre Islamic literature the nest of Simorgh is known to be on the tree of life and every time it seats on it the seed of all fruitful plants will fall down and every time it arises new branches with all fruitful seed of all plants will grow on them. Later this tree was changed to the Ghaf Mountain or association of the bird, tree and mountain have been painted together.

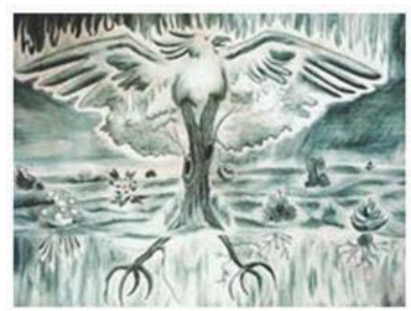

Figure 1. Typography of flower and bird with 4000 years age in Arak's Babakhani museum

Although this typography with the form of flower and bird which we know has many differences. It is very likely that the first association of flower and bird is taken from the myth of Simorgh and Tree of Life and later there were some artist who has painted the picture of Simorgh and holly tree in different forms. For example the picture of Simorgh has been pictured on tiling outside the Eight Paradise palace in Isfahan which belongs to the Patriarch's and Teimouri's era. This is a good example in this picture which could be more closely investigated:

This painting could be seen in one of the porches in Ganj-Alikhan complex in Kerman and as you can see, Simorgh has been painted very large and the branches of the flower has been drawn in a geometric shape.

\subsection{Flower and Morgh (Bird) in Iranian thought}

It is necessary to pay more attention to the Shahname and Sohrevardi Monograph of wit, since these two works have two different epic and Philosophical-mystic contexts and Simorgh also plays an important role in both of them. This is because in religious and literary texts of Zoroaster's faith, the Vispouyesh tree is considered the place of Simorgh. So the relation between Simorgh and tree could be a guidance to prove the hypothesis of social mindset continuation in the mold of plant and bird's myth. The mainstream of Shahnames' content which is a bridge between history and myth and as the greatest Iranian National epic is the integration between mythical history of ancient Iran and the thought of Islamic wisdom.

Tree in Shahname is recalled as the special tree in the fight between Rostam and Esfandiar which is the tree of Tamarisk. In the story of Rostam and Esfandiar in respect to Simorgh which is the symbol of divine wisdom, it is introduces as wizard, problem solver and therapist. As a matter of fact, in Shahname the tree and the sea have no relation with the position of Simorgh, even though Simorgh is defined exactly in the same mythical mold of Iranian ancient texts, but its nest is not on the tree, it is on the Alborz Mountain. Nevertheless, the relation between Simorgh and tree in Shahname has not been cut. In Shahname we read about the tree of Tamarisk: "Simorgh shows a Tamarisk tree to Rostam so to make an arrow and put a fire on it and shoot it with his two hands toward Esfandiars' eyes and defeat him. Some relations could be found between Tamarisk tree and ancient people's faith. "Tamarisk tree has some features that one of them is its localization in Sistan area, its suitability for making arrow, its unfruitfulness, its use in religious ceremonies, it is die hard in the burning area of desert and its medical properties" (Soltani, 1993, p 74). For same reason is that Simorgh uses it to kill invulnerable Esfandiar.

In the philosophical and mystic text there are some note about the trees which possess symbolic and mystic concepts that among them Sadr or Touba is the most important one. Avicenna notes: "... the Olive tree is the irony of 
thought, because it is talented with its own nature ... but after a lot of prowling and suffering a lot of pain, it has a potential to access the light and becomes light potential" (Sajady, 1984, p 56). This is one of the most profound and most beautiful concept which a tree can get it and grants it its symbolic value. But the most beautiful words in mentioned by Sohrevardi, Sheikh Al-Eshragh. He has a great role in integrating the Zoroaster Iranian wisdom and Islamic philosophy and renewal of ancient Iranian wisdom is debt to his struggle and renewal of Iranian wisdom and mysticism was his final goal. In his dissertation, Fee Halat Al-Toufoulie (about the state of childhood) he describes dark hearted people as patients with heart disease who have to pass three phases to be cured and get to the perfection of light:

"First, passing the worthless phase of being animal, that is to be insightful about the light of self and paying attention to the light factor of it. Second, passing the phase of being animal is completed when the very love, the essence of night lights (the moon) is appeared in your heart (the consciousness about integrating of rational self and active wisdom), third, going to the Ghaf mountain and eating the fruit of the tree (the tree of Touba) which Simorgh nests on it and from that time there is no need for anything, because the patient would be doctor himself and Hoopoe would change in the nature into Simorgh" (Soltani, 1993, p 222).

In the philosophical School of Sheikh Al-Eshragh, the tree of Touba could be identified as the first wisdom which from the illumination of the light of right on it, the other illuminated wisdoms would be appear and one of them is Simorgh or the active wisdom. So it reports from the language of red wisdom: "every moment a Simorgh flies up from the tree of Touba and from the 12 workshops of sky goes down toward the earth" (ibid, 223,224).

\section{Results}

From the preceding words it could be concluded that: After Islam's appearance and entrance in Iran, in addition to a different ideology which was pervasive as a heresy it was deeply integrated with the heritage of ancient Iran's religious and mythical believes. So that in drawing contrastive comparison between mythical symbols such as tree and Simorgh, not only we are not witness of content breaking between them, but we are somehow witness of an evolution. The tree of Vispouyesh is life giving and it has special features, it has the seed of all plants, it has healing effect and Simorgh nests on it, with these descriptions the tree of Touba is the same tree of Vispouyesh and Simorgh is the symbol of God itself. So Iranians did not see Islam as an obstacle against the direction of their art and thought, but they enriched their own beautiful believes which the most significant of them was the painting of the tree of life which according to the meaning and concept of this symbol it real value and its main origin is identified in Flower and Bird painting.

\section{References}

Aliadeh, M., (1997). "Dissertation about the history of Iran; Translation: Jalal Satary"; Cheh.3, Tehran: Soroush.

Amuzegar, J., A., (2002). "the mythical history of Iran". Second edition. Tehran, SAMT.

Ansari, M., (1999). "the values of Iranian Gardens (Safavi-Isfahan)"; PHD thesis; Tehran University; faculty of fine arts (Doctorial group of architecture).

Bahar, M., (1997). "a research in Iranian myths", Cheh-3; Tehran, Sepehr Naghsh.

Bahar, M., (2000). "Holly Tree: Etlaat Daily newspaper": Shin.2214, Sunday, January the $4^{\text {th }}$.

Dadgy, F., (2001). "Bandhesh: Gozarandeh": Mehrdad Bahar, Cheh.2: Tehran, Tous.

Devio, C., (1994). "live codes of life: Translation": Jalal Satary: Tehran: Markaz.

Doustkhah, J., (1982). "Avesta: Tehran: Morvarid Publication.

ail, P., 1998. "Aboulghasem; myth the symbolic expression", Tehran, Soroush.

Fatemeh, M., (2011). "Descriptive Culture of critics and literary ideas"; Academy of Human Science and cultural research, Tehran.

Hinlez, J., (1989). "understanding of Iranian myths; Translation": Jaleh Amuzegar and Ahmad Tafazoly; Tehran, Cheshmeh.

Holly Quran

Jim Vany, Alef,. (2000). "Art and symbol (tree)": Science and Research Journal, Art book, Shin. 7, summer of.

Lingz, M., (1998). "the Art of Quran Callygraphy and illumination"; Translation: Mehrdad Ghayumi Bid Hendy; Tehran: Garous.

Marzban, P., (1998). "Marouf, Heh; A Pictorial encyclopedia in Visual Arts of Parch"; 3: Tehran, Soroush,.

Mir Shokrayi, M., (2000). "visti of Houm; The book of Moon (Art)". Shin.25 and 26, October and November.

Pournamdarian, T., (1995). "Codes and Iranian Code Stories, Cheh-4": Tehran: Science and Culture Journal.

Sajady, Sin, Shahab Al-Din "Sohrevardi and a survy in Eastern Philosophy; Tehran: Phisosophy; 1984.

Salehi, B., (1993). Tree, "a universal symbol: the thesis in Bacholor of Pictorial communication; "Tehran University, Faculty of Fine Arts.

Samady, (1988). "Moon in Iran (Up to Islam Apearance)"; Terhan: Science and Culture.

Shahdadi, J., (2013). "Flower and Bird (Morgh)"; Cheh02, Tehran: The book of sun.

Shams, A., (2000). "A review of signs and symbols in ancient Iran": Journal of Visual Arts, Shin, 8, Spring of.

Soltani Gard Faramarzi,.(1993). "Ein; Simorgh in the Iranian culture Territory"; Tehran, Mobtakeran. 